\title{
Endovascular approaches in pediatric interventional oncology
}

\author{
Raja Shaikh ${ }^{1^{*}}$ and Fernando Gomez Munoz ${ }^{2}$
}

\begin{abstract}
The demand for interventional oncological $(\mathrm{IO})$ treatment of pediatric cancers is becoming increasingly common, at least at several tertiary care institutions. The data and techniques used in pediatric $1 O$ are largely extrapolated from experience in adult patients. The management of pediatric tumors differs from that in adults in several categories, such as, the curative intent of treatment, wide use of general anesthesia, aggressive pain management, potentially longer hospital stay, variation in chemotherapy dosing etc. Additionally, pediatric cancers are managed by protocols directed by national and international oncology groups such as the Children's Oncology Group (COG).

Consequently, the translation and adoption of these techniques is gradual, but there is a noticeable uptrend due to the growing need. This review will update the current endovascular 10 treatments for common pediatric liver, renal, bone and soft tissue tumors.
\end{abstract}

Keywords: Interventional oncology, Pediatric tumors, Children's oncology, Hepatocellular carcinoma, Hepatoblastoma, Neuroblastoma, Sarcoma, Retinoblastoma, Tumor bleeding, Tumor embolization

\section{Background}

Pediatric interventional oncology (IO) practice is mainly based off the adult IO experience, although there exist inherent differences between the two groups. While cancers occurring in adults are classified by the anatomical site of the primary tumor, cancers in children and younger adolescents are classified by histology (tissue type) into 12 major groups using the International Classification of Childhood Cancers (ICCC). Extracranial malignant pediatric solid tumors represent $52 \%$ of cancers in the 15- to 19-year-old-age group with germ cell tumors being the most common. In younger children, embryonal cancers, retinoblastoma, neuroblastoma, and hepatoblastoma, are more prevalent. The most common malignant solid tumors in adolescents are extracranial germ cell tumors (GCTs), bone and soft tissue sarcomas, melanoma and thyroid cancer (Allen-Rhoades et al. 2018).

\footnotetext{
* Correspondence: drrajashaikh@yahoo.com

'Department of Radiology, Boston Children's Hospital and Harvard Medical

School, 300 Longwood, Boston MA-02115, USA

Full list of author information is available at the end of the article
}

Catheter directed chemotherapy regimens are relatively new and unfamiliar in pediatric setting. The decision making process often demands close discussion involving all care givers. Due to the developing physiological processes, adult chemotherapy dosing, cannot be applied in children as this may cause variable medication exposure, clearance, toxicity and unpredictable efficacy. Body surface area (BSA) based chemotherapy dosing used in adults can greatly overestimate the dose in younger children, where body weight may more accurately predict drug exposure (Leahey 2012; Veal and Boddy 2012). These variations warrant careful considerations and treatment planning. Use of general anesthesia, support from child psychology in preparation for invasive procedures is common in pediatric practice unlike that in adults (Temple and Marshalleck 2014). Arterial spasm and dissection are more common in children which may impede very distal selective catheterization and use of large caliber catheters. Post-embolization syndrome is also more common in children and often needs good supportive care and longer hospital admission (Temple and Marshalleck 2014; Bissler et al. 2002). Despite these impediments, there is an evident increase in the interest 
for these techniques. An example of this is a comparison between the number of indexed publications on interventional oncology for the management of pediatric malignancies in PubMed. Between 2010 and 2014, there were less than 180, and between 2015 and 2019, there were greater than 450 relevant publications. Percutaneous biopsy, percutaneous ablation, bland embolization, chemoembolization, radioembolization, combined percutaneous therapies or combination of systemic plus locoregional therapies are becoming more common among pediatric oncological treatments and represents an opportunity for interventional radiologists. This MEDLINE based review used relevant keywords to identify current literature in endovascular treatment of cancers in children.

\section{Liver tumors}

Hepatoblastoma and hepatocellular carcinomas (HCC) are the predominant primary liver malignancies (1\% of pediatric malignancies) in children. Hepatoblastoma accounts for two thirds of malignant liver tumors in children. Other liver malignancies in children include hepatocellular carcinoma, sarcomas, germ cell tumors and rhabdoid tumors. Benign tumors of the liver in children include vascular tumors, hamartomas and adenomas (Litten and Tomlinson 2008). In contrast to adults, HCC in children occur in normal livers without underlying cirrhosis, and a smaller proportion occur in the background of chronic liver diseases (Lungren et al. 2018). Staging and treatment decisions for pediatric liver tumors are based on guidelines from the three principal international cooperative groups that study childhood liver cancer: Children's Oncology Group (COG), Société Internationale d'Oncologie Pédiatrique Epithelial Liver group (SIOPEL), and the Japanese Pediatric Liver Tumor Study Group (JPLT). The PRETEXT (PRETreatment EXTent of disease) and POST-TEXT, proposed by SIOPEL, is used in staging of pediatric HCCs.

\section{Bland embolization}

In liver, bland embolization has been used to treat hepatic adenomas (Deodhar et al. 2011), ruptured hepatocellular carcinomas (Yamada et al. 2015), hepatoblastomas (in preparation for surgery) (Krauel et al. 2009), focal nodular hyperplasia (Oliveira et al. 2015) and vascular tumors such as hemangiomas (Sun et al. 2015; Kullendorff et al. 2002). Due to smaller blood volume in children, especially infants, uncontrolled blood loss can prove catastrophic during resection or tumor rupture, especially with hypervascular tumors. A variety of embolic agents can be used such as poly vinyl alcohol (PVA) microparticles of varying sizes, tris-acryl gelatin microspheres (Embosphere, Biosphere Medical, Rockland, MA), pledgets of gelatin sponge (Gelfoam,
Pfizer, New York, NY, USA) and microfibrillar collagen (Tsochatzis 2014; Kishore 2017). Typically, particle sizes $100-300 \mu \mathrm{m}$ are favored because smaller particles can cause biliary necrosis and bilomas and larger particles do not cause sufficient tumor ischemia (Lungren et al. 2018). Liquid embolization agents include $n$-butylcyanoacrylate (nBCA; Trufill nBCA Liquid Embolic, Codman Neurovascular Inc., Raynham, MA, USA), ethyl vinyl alcohol polymer (Onyx, eV3 Endovascular Inc., Irvine, CA, USA) and ethanol. Occlusion of large arterial feeders may require use of pushable or detachable coils. Often a combination of these agents may be used.

\section{Transcatheter arterial chemoembolization (TACE)}

This procedure increases the intratumoral concentration of the chemotherapeutic medication (most commonly doxorubicin) with the embolization aspect increasing the dwell time of the medication inside the target tissue while reducing the amount of drug entering the systemic circulation. The hypoxia and ischemia induced by TACE further augment the chemotherapy dose achieved within the neoplastic tissue. Chemoembolization has been utilized as neoadjuvant or to treat non-resectable liver hepatoblastoma (Hishiki 2013; Vogl et al. 2006; Tan et al. 2014) or hepatocellular carcinoma (Arcement et al. 2000). Recently, in a series of 8 patients (4-17 years) with unresectable HCCs, there was change in tumor volume by $51 \%$, change in alfa fetoprotein level by $-49.6 \%$, successful bridge to orthotopic liver transplantation with mean interval of 141 days (Weiss et al. 2018). TACE has also been advocated as a bridge therapy for liver transplantation (Hishiki 2013; Weiss et al. 2018; Li et al. 2008) (Fig. 1). In simple setting, TACE can be performed as an emulsion of the chemotherapeutic with an oilbased contrast medium such as ethiodized oil. Increasingly, vendor supplied, size specific drug-eluting beads (DEB $100-300 \mu \mathrm{m}$ or $300-500 \mu \mathrm{m}$ ), which are then impregnated with the chemotherapeutic agents within onco-pharmacy, are being used to inject into the tumor. Other liver neoplasms treated by TACE include primary angiosarcoma or metastases from different primary tumors (Malogolowkin et al. 2000; Escobar Jr. et al. 2017; Cazejust et al. 2010; Mutabagani et al. 1999). A potential role of TACE is the treatment of PRETEXT I and II hepatoblastoma as neoadjuvant or adjuvant therapy to increase necrosis and potentially reduce relapse (alone or in combination with systemic therapy). Tumor necrosis, following neoadjuvant treatment, serves as a predictor for patient survival, especially in hepatoblatomas with undifferentiated small cells (Venkatramani et al. 2012). In the PRETEXT III or IV, TACE could be used to increase necrosis and hypothetically reduce relapse when used alone or in combination with systemic therapy. 

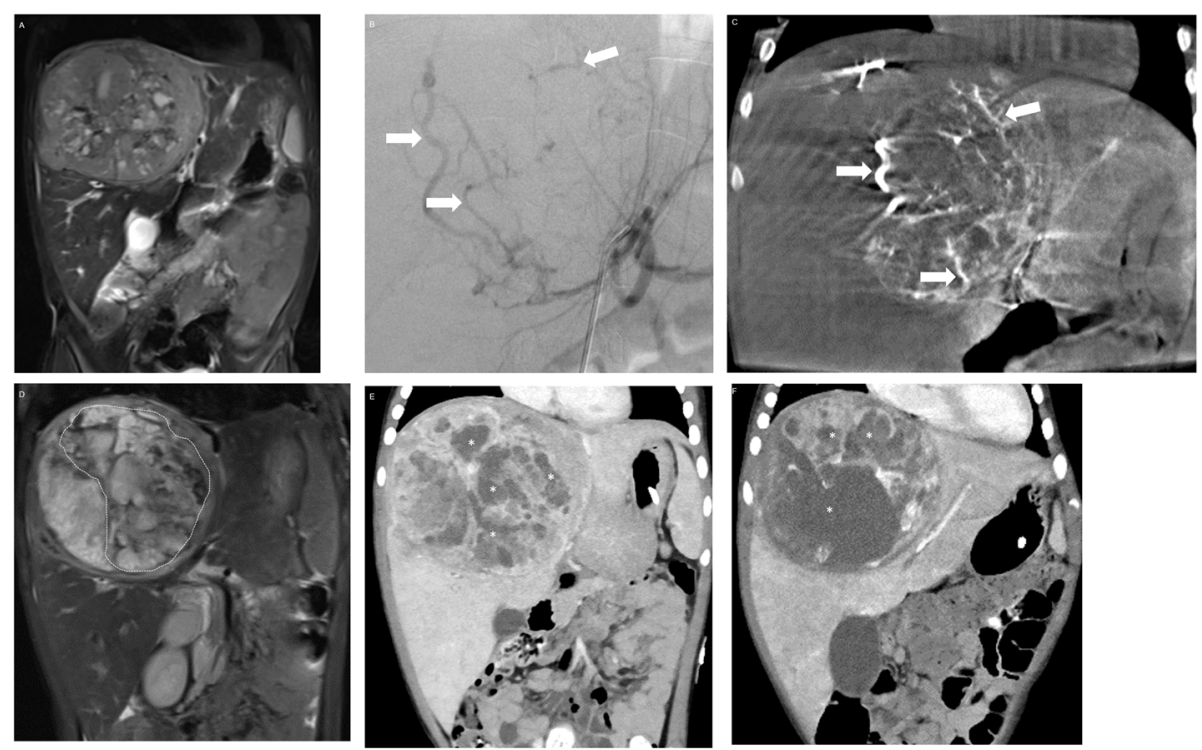

Fig. 1 T2- weighted fat saturated coronal (a) MR image demonstrating a large hepatocellular carcinoma in a 2-year-old male patient which was unresponsive to systemic chemotherapy. b Angiography obtained during transcatheter arterial chemoembolization demonstrating several hepatic arterial branches encasing and supplying the tumor (arrows). These feeders were injected with $30 \mathrm{mg}$ of doxorubicin emulsified with lipiodol followed by embolization with 150-250- $\mu$ m poly vinyl alcohol particles confirmed on cone-beam computed tomography (c) obtained post embolization demonstrating the radio-opaque embolization beads in the tumor bed (arrows). d Post embolization T1- weighted post contrast coronal MRI obtained 3 weeks later demonstrating heterogeneous necrotic area (dotted line) within the tumor. Coronal computed tomography obtained 3 weeks (e) after the first TACE procedure and 3 weeks ( $\mathbf{f}$ ) after the second TACE procedure demonstrating increasing necrotic areas within the tumor (asterisk). The patient underwent a successful liver transplant 6 weeks later

\section{Trans arterial radio embolization (TARE)}

This involves selective catheter implantation of yttrium$90\left({ }^{90} \mathrm{Y}\right)$, which are $\beta$ radiation $(0.97 \mathrm{mEv})-$ emitting radioisotopes, directly into the tumor mass by means of glass (Theraspheres; MDS Nordion, Ottawa, Canada) or resin (SIR-Spheres; Sirtex, North Sydney, Australia) microspheres. This provides targeted brachytherapy without the systemic side effects of radiation. This technique is frequently used to treat primary and secondary liver tumors in adults. Yttrium-90 decays to stable zirconium90 with a physical half-life of $64.2 \mathrm{~h}$. The mean tissue penetration of the energy emitted (average $0.9367 \mathrm{MeV}$, Maximum $2.27 \mathrm{MeV}$ ) is $2.5 \mathrm{~mm}$ with a maximum of 11 $\mathrm{mm}$ (Lungren et al. 2018). This application, although limited in availability, has been used in the pediatric setting (Hawkins et al. 2013). Alternatively, Holmium-166 can also be used to perform radioembolization, however there is no report of its use in children. This treatment modality could be considered in patients who do not have a chemotherapy-sensitive tumor or when toxicity limits have been reached from previous chemotherapy. It is critical to perform preliminary planning prior to radioembolization which involves appropriate patient workup and preparation, arterial mapping studies, embolization of nontarget collaterals and evaluation of pulmonary shunt fraction. In selected settings, there may be role for preoperative portal vein embolization to promote hypertrophy of the liver prior to partial hepatectomy by radioembolization. At the time of this publication, only 12 patients treated with radioembolization for liver tumors has been reported (Hawkins et al. 2013; Aguado et al. 2019). Potential indications of radioembolization in children may include patients with nonresectable liver malignancies such as hepatoblastoma, hepatocellular carcinoma or metastases as palliation or with curative intent or as a bridge to liver transplantation (Lungren et al. 2018).

Portal vein embolization has been used to promote the growth of the future liver remnant when insufficient liver volume can be predicted before hepatectomy in liver tumors. This has been used in toddlers with hepatoblastoma and mesenteric hamartoma to aid trisegmentectomy and hepatectomy by embolizing with the tumor feeding vessels with PVA and ethylene-vinyl alcohol copolymer (Onyx 18, ev3, France) respectively (Le et al. 2018; Terraz et al. 2015).

\section{Renal and suprarenal tumors}

Wilms tumor is the most common malignant renal tumor of childhood accounting for accounts for about $6 \%$ of all malignant tumors in children. These tumors can be unresectable when tumor diameter is greater 
than or equal to $10 \mathrm{~cm}$, when there is involvement of adjacent vital structures and if there is intracaval/atrial extension of the tumor. Pre-operative TACE with short term systemic chemotherapy with emulsion of pirarubicin, vindesine, cisplatin has been shown to be helpful in treatment of unresectable, metastatic, or diffuse anaplastic histology Wilms' tumor with higher rates of complete tumor resection and relapse-free survival ( $\mathrm{Li}$ et al. 2016; $\mathrm{Li}$ et al. 2011). Tumor necrosis was $>90 \%$ in 14 (25.5\%), $50 \%-90 \%$ in $23(41.8 \%)$, and $<50 \%$ in 18 cases $(32.7 \%)$. 5 -year event-free survival was $92.7 \%$, and the overall survival was $94.5 \%$. No drug-induced cardiotoxicity, nephrotoxicity or hepatic dysfunction was observed. Bland embolization has been performed in Wilm's tumor to control hematuria after biopsy or treat lifethreatening hemorrhage prior to nephrectomy (Smith et al. 2005; Chitnis et al. 2004).

Renal angiomyolipomas (AML) at a younger age, is aggressive and typically represents a component of tuberous-sclerosis-complex (Anis et al. 2020). The tumor comprising of fat and smooth muscle elements have a more than $50 \%$ risk of rupture and hemorrhage when greater than $4 \mathrm{~cm}$ in diameter (Rimon et al. 2006). Transcatheter renal artery embolization can be performed for hemorrhage from angiomyolipomas eliminating the need for blood transfusion and surgery in technically successful cases and, decrease tumor size in non-hemorrhagic AML (Hamlin et al. 1997; Dabbeche et al. 2006; Bardin et al. 2017; El Rafei et al. 2015). Transarterial embolization can be considered a safe primary option for symptomatic or larger AML (Anis et al. 2020). In patients with hematuria from renal tumors, such as, malignant rhaboid tumor, embolization can be performed to stop bleeding and facilitate chemotherapy (Sharma et al. 2013).

Similar to Wilm's tumor, presurgical embolization can be performed in large neuroblastomas to reduce intraoperative bleeding at resection, treat bleeding after biopsy and shrink the tumor to decrease intraabdomial pressure and improve respiratory status (Krauel et al. 2009; Kyo Jin et al. 2018; Pio et al. 2017). A maximum primary tumor diameter $>13.20 \mathrm{~cm}$ and $M Y C N$ gene amplification were two independent risk factors for high-risk $\mathrm{NB}$ tumor rupture (Qin et al. 2020).

\section{Bone and soft tissue tumors}

Malignant bone tumors account for $6 \%$ of all childhood malignancies, $56 \%$ of which are osteosarcomas and $34 \%$ are Ewing sarcomas with peak incidence at 15 years of age (Gereige and Kumar 2010). Bland embolization can be used, both for local control and symptom palliation, in bone tumors (Mavrogenis et al. 2014). Surgery remains the standard treatment for osteosarcomas with adjunctive systemic chemotherapy, but transarterial chemoembolization in combination with limb salvage surgery yielded encouraging results when used to treat 32 patients with osteosarcoma prior to limb salvage surgery (Owen 2010) (Fig. 2). Chemoembolization with intra-arterial methotrexate has been used to treat resistant osteosarcoma (Avritscher and Javadi 2011). Preoperative embolization has proven to be an effective therapy in giant cell tumors, aneurysmal bone cysts, osteoblastomas, chondrosarcomas and vertebral hemangiomas to reduce blood loss and decrease transfusion requirements (Jha et al. 2016; Owen 2010; Pazionis et al. 2014; Ibrahim et al. 2013; Li et al. 2008; Boztug et al. 2006). Aneurysmal bone cysts $(A B C)$ are benign bone tumors of childhood and early adulthood presenting as expansile osteolytic lesions with a varying potential to be locally aggressive. Embolization has been used for the treatment of $A B C s$, especially in locations where surgical management is difficult and associated with a substantial risk for complications, and also to minimize bleeding during excision (Rossi et al. 2010; Amendola et al. 2013; Donati et al. 2011; Boriani et al. 2014; Pearl et al. 2012) (Fig. 3).

Doxorubicin administered by means of eluting beads for extra-abdominal desmoid tumors has shown promising results, among 4 children suffering recurrent or refractory desmoid tumors. This approach demonstrated reduction of tumor volumes ranging from $54 \%$ to $97 \%$ over a follow-up interval of 6-32 months (Elnekave et al. 2018). Also, neoadjuvant intra-arterial infusion of cisplatin, pirarubicin, and vindesine for rhabdomyosarcoma and endodermal sinus tumor has been performed ( $\mathrm{Wu}$ et al. 2016). Bland embolization has been used in metastatic paraganglioma, myofibroblastic tumor, osteosarcoma and undifferentiated sarcoma to help in preparation for surgery, treat life-threatening event and for palliative care (Krauel et al. 2009) (Fig. 4). In very young infants, large $(>10 \mathrm{~cm})$, sacrococcygeal teratomas pose risk of rupture and profuse bleeding before or during resection in whom preoperative embolization has been safely performed to mitigate the increased bleeding risk (Lahdes-Vasama et al. 2011; Cowles et al. 2006; Stavropoulou et al. 2019).

\section{Intracranial tumors}

Hypervascular pediatric brain tumors such as choroid plexus papilloma, meningioma, astrocytoma, hemangioblastoma, yolk sac tumors and skull base tumors can be embolized pre-operatively to reduce blood loss (Wang et al. 2013; Amuluru et al. 2016). Currently a phase I/II trial is on for evaluating the role of intra-arterial infusion of Cetuximab and Bevacizumab for the treatment of relapsed or refractory intracranial gliomas in patients below 22 years (Health 2013). 

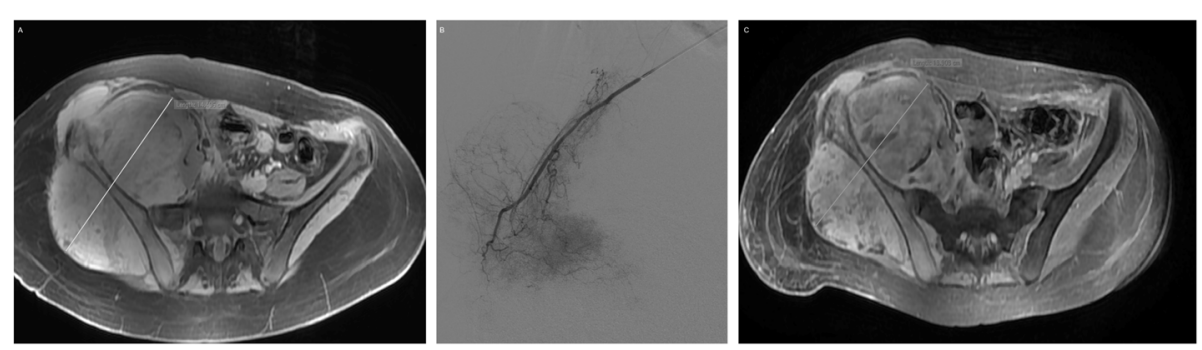

Fig. 2 a T1-weighted fat saturated gadolinium (gd) axial MR image demonstrating a large pelvic osteosarcoma (biopsy proven) in a 14-year-old female. b Digital subtraction angiography demonstrating arterial tumor blush from branches of the internal iliac artery. These feeders were embolized with 100-300 DC beads loaded with $100 \mathrm{mg}$ of doxorubicin (DEBDOX-TACE). c T1-weighted fat saturated gadolinium (gd) axial MR image at 1-month demonstrating reduction in tumor size with intra-tumoral necrosis

\section{Retinoblastoma}

Intra-arterial infusion chemotherapy with melphalan as the chemotherapeutic agent, is well-established for the treatment of retinoblastoma (Manjandavida et al. 2019). Targeted treatment in retinoblastoma by direct delivery of chemotherapeutic agents into the ophthalmic artery (OA) has dramatically changed the approach in the management of this deadly, yet curable eye cancer (Shields and Shields 2010; Anderson et al. 2017; Wyse et al. 2016). Inomato and Kaneko, in their initial series, used melphalan as single-agent chemotherapeutic drug for IAC (Inomata and Kaneko 1987). Abramson et al. added carboplatin and topotecan, which initiated the triple-drug regimen (Abramson et al. 2008; Gobin et al. 2011).

\section{Miscellaneous}

Six children with different malignancies (acute lymphoblastic leukemia, acute myelogenous leukemia, chronic myelogenous leukemia, T-cell prolymphocytic leukemia, Langerhans cell histiocytosis, and rhabdomyosarcoma) had selective internal iliac arterial embolization with gelfoam and coils for hemorrhagic cystitis following stem cell transplantation (Bae et al. 2011).

\section{Future directions}

Combined techniques, which use endovascular approaches for drug delivery with percutaneous tumor ablation techniques are being trialed in adults to test for greater treatment efficacy (Liapi and Geschwind 2007). If successful, such techniques could potentially be applied in pediatric patients. Immunoembolization is being trialed for metastatic uveal melanoma in adults, which similarly, could be expanded to pediatric patients (Institute 2018). Nano-particles coated with chemotherapeutic drugs or genetic agents could be delivered via endovascular route into the tumor. Certain specific aspects of the tumor, including immune response, oncogenic expression, susceptibility to chemotherapeutics, or its genetic potential, may be altered using these techniques.

\section{Conclusion}

The lack of substantial evidence is one of the major drawbacks for wider acceptance of pediatric endovascular interventional oncological treatments. Creation of large multi institutional registries and repositories can help provide data base to study the efficacy and safety of these treatments on a larger scale. Additionally, involvement and partnership with organizations such as the Children's Oncology Group, participation in clinical
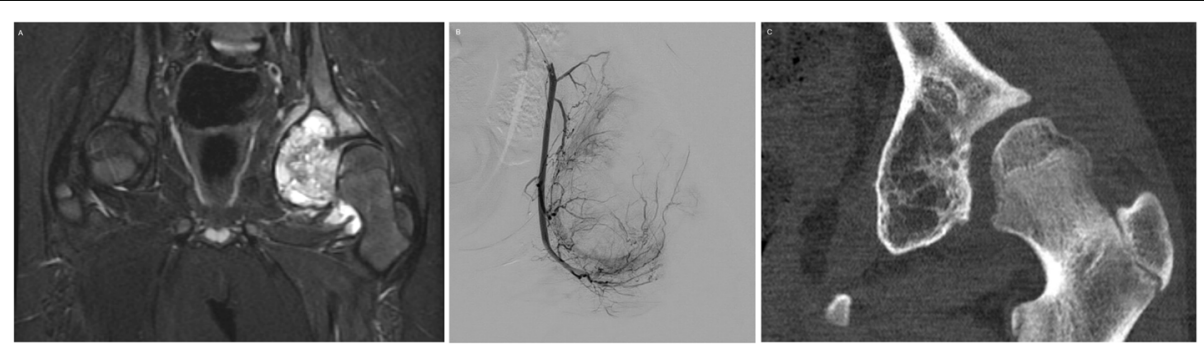

Fig. 3 a Short tau inversion recovery (STIR) weighted coronal MR image demonstrating an expansile aneurysmal bone cyst of the left acetabulum in a 10-year-old male. $\mathbf{b}$ Digital subtraction angiography demonstrating arterial tumor blush from branches of the obturator artery. These feeders were embolized with 25\% N-butyl cyanoacrylate and Lipiodol mixture. c Follow-up coronal CT image obtained 24-months after embolization demonstrating decrease in size of the $A B C$ with ossification 

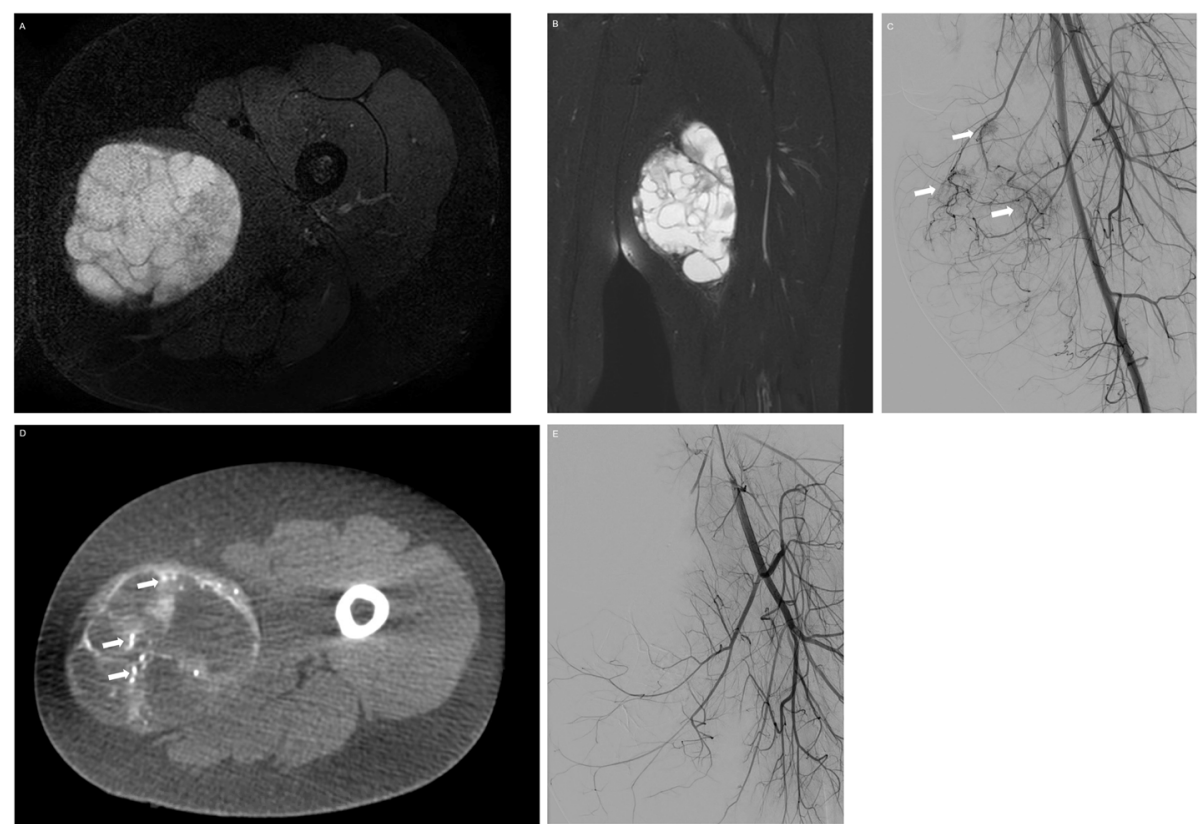

Fig. 4 T2- weighted fat saturated axial (a) and coronal (b) MR image demonstrating a soft tissue sarcoma (malignant hemangiopericytoma) in the thigh of a 10-year-old male. A pre-resection embolization was requested due to its hypervascularity and risk of bleeding during surgery. c Preoperative angiography demonstrating arterial tumor blush from branches of the superficial and deep femoral arteries (arrows). These feeders were embolized with 70-150 DC bead LUMI to reduce bleeding during resection. $\mathbf{d}$ Axial cone beam CT image obtained post embolization demonstrating the radio-opaque embolization beads in the tumor bed (arrows). e Post embolization angiography demonstrating disappearance of the arterial tumor blush

trials such as the pediatric hepatic international tumor trial (PHITT) in collaboration with other pediatric oncology care specialties would add value to this subspecialty. Creation and standardization of practice protocols and post treatment assessment indices will be necessary to substantiate the role of pediatric IO. However, pediatric care givers need to be aware of this modality so that it can be complemented with other cancer treatment modalities such as radiation, medical and surgical oncology in the wider management of pediatric cancers. This will help create a referral base to allow collection of additional experience in this field and create controlled prospective studies that will add to current knowledge on endovascular treatment in pediatric cancers.

\section{Authors' contributions}

RS and FG contributed and reviewed all topics. The authors read and approved the final manuscript.

\section{Funding}

I have a waiver from the Editor-in-Chief.

\section{Availability of data and materials}

NA.

Ethics approval and consent to participate

This was a review article and therefore no approval was required.

\section{Consent for publication}

No individual personal data was used and therefore no consent was required.

\section{Competing interests}

None.

\section{Author details}

'Department of Radiology, Boston Children's Hospital and Harvard Medical School, 300 Longwood, Boston MA-02115, USA. ${ }^{2}$ Hospital Clinic-Hospital Sant Joan de Deu, C/ Villarroel 170, Passeig de Sant Joan de Déu, 2, Esplugues del Llobregat, 08950 Barcelona, Spain.

Received: 10 September 2020 Accepted: 2 December 2020

Published online: 02 January 2021

\section{References}

Abramson DH, Dunkel IJ, Brodie SE, Kim JW, Gobin YP (2008) A phase I/II study of direct intraarterial (ophthalmic artery) chemotherapy with melphalan for intraocular retinoblastoma initial results. Ophthalmology 115(8):1398-1404, 1404 e1391. https://doi.org/10.1016/j.ophtha.2007.12.014

Aguado A, Ristagno R, Towbin AJ, Gupta A, Haberle S, Qi Z, Patel MN, Kukreja KU, Tiao GM, Geller II (2019) Transarterial radioembolization with yttrium-90 of unresectable primary hepatic malignancy in children. Pediatr Blood Cancer 66(7):e27510. https://doi.org/10.1002/pbc.27510

Allen-Rhoades W, Whittle SB, Rainusso N (2018) Pediatric solid tumors in children and adolescents: an overview. Pediatr Rev 39(9):444-453. https://doi.org/10. 1542/pir.2017-0268

Amendola L, Simonetti L, Simoes CE, Bandiera S, De lure F, Boriani S (2013) Aneurysmal bone cyst of the mobile spine: the therapeutic role of embolization. Eur Spine J 22(3):533-541. https://doi.org/10.1007/s00586-0122566-7 
Amuluru K, Almufti F, Singh I, Prestigiacomo C, Gandhi C (2016) Embolization of pediatric intracranial and Skull Base vascular tumors. https://doi.org/10.1007/ 978-3-319-43636-4_19

Anderson HJ, Pointdujour-Lim R, Shields CL (2017) Treatments for retinoblastoma then and now. JAMA Ophthalmol 135(1):e164652. https://doi.org/10.1001/ jamaophthalmol.2016.4652

Anis O, Rimon U, Ramon J, Khaitovich B, Zilberman DE, Portnoy O, Dotan ZA (2020) Selective arterial embolization for large or symptomatic renal Angiomyolipoma: 10 years of follow-up. Urology 135:82-87. https://doi.org/ 10.1016/j.urology.2019.09.035

Arcement CM, Towbin RB, Meza MP, Gerber DA, Kaye RD, Mazariegos GV, Carr BI, Reyes J (2000) Intrahepatic chemoembolization in unresectable pediatric liver malignancies. Pediatr Radiol 30(11):779-785. https://doi.org/10.1007/ s002470000296

Avritscher R, Javadi S (2011) Transcatheter intra-arterial limb infusion for extremity osteosarcoma: technical considerations and outcomes. Tech Vasc Interv Radiol 14(3):124-128. https://doi.org/10.1053/j.tvir.2011.02.004

Bae SH, Han DK, Baek HJ, Park SJ, Chang NK, Kook H, Hwang TJ (2011) Selective embolization of the internal iliac arteries for the treatment of intractable hemorrhage in children with malignancies. Korean J Pediatr 54(4):169-175. https://doi.org/10.3345/kjp.2011.54.4.169

Bardin F, Chevallier O, Bertaut A, Delorme E, Moulin M, Pottecher P, Di Marco L, Gehin S, Mourey E, Cormier L, Mousson C, Midulla M, Loffroy R (2017) Selective arterial embolization of symptomatic and asymptomatic renal angiomyolipomas: a retrospective study of safety, outcomes and tumor size reduction. Quant Imaging Med Surg 7(1):8-23. https://doi.org/10.21037/qims. 2017.01.02

Bissler JJ, Racadio J, Donnelly LF, Johnson ND (2002) Reduction of postembolization syndrome after ablation of renal angiomyolipoma. Am J Kidney Dis 39(5):966-971. https://doi.org/10.1053/ajkd.2002.32770

Boriani S, Lo SF, Puvanesarajah V, Fisher CG, Varga PP, Rhines LD, Germscheid NM, Luzzati A, Chou D, Reynolds JJ, Williams RP, Zadnik P, Groves M, Sciubba DM, Bettegowda C, Gokaslan ZL, Tumor AOKF (2014) Aneurysmal bone cysts of the spine: treatment options and considerations. J Neuro-Oncol 120(1): 171-178. https://doi.org/10.1007/s11060-014-1540-0

Boztug K, Kiely E, Roebuck DJ, Gaze M, Begent J, Brock P, Michalski A (2006) Successful treatment of MYCN amplified, progressive stage $4 \mathrm{~S}$ neuroblastoma in a neonate with hepatic artery embolization in addition to multimodality treatment. Pediatr Blood Cancer 46(2):253-257. https://doi.org/ 10.1002/pbc.20407

Cazejust J, De Baere T, Auperin A, Deschamps F, Hechelhammer L, Abdel-Rehim M, Schlumberger M, Leboulleux S, Baudin E (2010) Transcatheter arterial chemoembolization for liver metastases in patients with adrenocortical carcinoma. J Vasc Interv Radiol 21(10):1527-1532. https://doi.org/10.1016/j.jvir. 2010.05.020

Chitnis M, Chowdhary SK, Lazarus C (2004) Preoperative angioembolisation for life-threatening haemorrhage from Wilms' tumour: a case report. Pediatr Surg Int 20(4):290-291. https://doi.org/10.1007/s00383-003-1128-9

Cowles RA, Stolar CJ, Kandel JJ, Weintraub JL, Susman J, Spigland NA (2006) Preoperative angiography with embolization and radiofrequency ablation as novel adjuncts to safe surgical resection of a large, vascular sacrococcygeal teratoma. Pediatr Surg Int 22(6):554-556. https://doi.org/10.1007/s00383-0061650-7

Dabbeche C, Chaker M, Chemali R, Perot V, El Hajj L, Ferriere JM, Ballanger P, Chabbert V, Cimpean A, Otal P, Huyghe E, Grenier N, Joffre F (2006) Role of embolization in renal angiomyolipomas. J Radiol 87(12 Pt 1):1859-1867. https://doi.org/10.1016/s0221-0363(06)74166-x

Deodhar A, Brody LA, Covey AM, Brown KT, Getrajdman Gl (2011) Bland embolization in the treatment of hepatic adenomas: preliminary experience. J Vasc interv Radiol 22(6):795-799; quiz 800. https://doi.org/10.1016/j.jvir.2011.02.027

Donati D, Frisoni T, Dozza B, DeGroot H, Albisinni U, Giannini S (2011) Advance in the treatment of aneurysmal bone cyst of the sacrum. Skelet Radiol 40(11): 1461-1466. https://doi.org/10.1007/s00256-011-1202-7

El Rafei M, Renard B, Puech P, Devos P, Gaillard V, Lemaitre L (2015) Tumor necrosis after preventive embolization of large renal angiomyolipomas. Diagn Interv Imaging 96(6):579-587. https://doi.org/10.1016/j.diii.2015.01.008

Elnekave E, Atar E, Amar S, Bruckheimer E, Knizhnik M, Yaniv I, Dujovny T, Feinmesser M, Ash S (2018) Doxorubicin-eluting intra-arterial therapy for pediatric extra-abdominal Desmoid Fibromatoses: a promising approach for a perplexing disease. J Vasc interv Radiol 29(10):1376-1382. https://doi.org/ 10.1016/j.jvir.2018.04.009
Escobar MA Jr, McClellan JM, Thomas W (2017, 2017) Solid pseudopapillary tumour (Frantz's tumour) of the pancreas in childhood: successful management of late liver metastases with sunitinib and chemoembolisation. BMJ Case Rep. https://doi.org/10.1136/bcr-2017-221906

Gereige R, Kumar M (2010) Bone lesions: benign and malignant. Pediatr Rev 31(9):355-362; quiz 363. https://doi.org/10.1542/pir.31-9-355

Gobin YP, Dunkel IJ, Marr BP, Brodie SE, Abramson DH (2011) Intra-arterial chemotherapy for the management of retinoblastoma: four-year experience. Arch Ophthalmol 129(6):732-737. https://doi.org/10.1001/archophthalmol. 2011.5

Hamlin JA, Smith DC, Taylor FC, McKinney JM, Ruckle HC, Hadley HR (1997) Renal angiomyolipomas: Iong-term follow-up of embolization for acute hemorrhage. Can Assoc Radiol J 48(3):191-198

Hawkins CM, Kukreja K, Geller Jl, Schatzman C, Ristagno R (2013) Radioembolisation for treatment of pediatric hepatocellular carcinoma. Pediatr Radiol 43(7):876-881. https://doi.org/10.1007/s00247-012-2568-y

Health Nlo (2013) Intraarterial Infusion Of Erbitux and Bevacizumab For Relapsed/ Refractory Intracranial Glioma In Patients Under, vol 22 https://clinicaltrials. gov/ct2/show/NCT01884740. Accessed 24 June 2013

Hishiki T (2013) Current therapeutic strategies for childhood hepatic tumors: surgical and interventional treatments for hepatoblastoma. Int J Clin Oncol 18(6):962-968. https://doi.org/10.1007/s10147-013-0625-7

Ibrahim WH, Safran ZA, Hasan H, Zeid WA (2013) Preoperative and therapeutic embolization of extremities of bone and soft tissue tumors. Angiology 64(2): 151-156. https://doi.org/10.1177/0003319711436075

Inomata M, Kaneko A (1987) Chemosensitivity profiles of primary and cultured human retinoblastoma cells in a human tumor clonogenic assay. Jpn J Cancer Res 78(8):858-868

Institute NC (2018) Ipilimumab and Nivolumab With Immunoembolization in Treating Participants With Metastatic Uveal Melanoma in the Liver. https:// clinicaltrials.gov/ct2/show/NCT03472586. Accessed 21 Mar 2018

Jha R, Sharma R, Rastogi S, Khan SA, Jayaswal A, Gamanagatti S (2016) Preoperative embolization of primary bone tumors: a case control study. World J Radiol 8(4):378-389. https://doi.org/10.4329/wjr.v8.i4.378

Kishore S, Friedman T, Madoff DC (2017) Update on Embolization Therapies for Hepatocellular Carcinoma. Curr Oncol Rep 19(6):40. https://doi.org/10.1007/ s11912-017-0597-2

Krauel L, Albert A, Mora J, Sola T, Cruz O, Mortera C, Ribo JM (2009) Use of angioembolization as an effective technique for the management of pediatric solid tumors. J Pediatr Surg 44(9):1848-1855. https://doi.org/10. 1016/j.jpedsurg.2009.04.037

Kullendorff CM, Cwikiel W, Sandstrom S (2002) Embolization of hepatic hemangiomas in infants. Eur J Pediatr Surg 12(5):348-352. https://doi.org/10. 1055/s-2002-35949

Kyo Jin J, , Eu Jeen Y, Kyung Mi P, Jin Heyok K, Ung Bae J, Joo Yeon J, Young Tak L, (2018) Two pediatric cases of spontaneous ruptured solid tumors successfully treated with transcutaneous arterial embolization. Clin Pediatr Hematol Oncol 25 (2):197-201

Lahdes-Vasama T, Korhonen PH, Seppanen JM, Tammela OK, Iber T (2011) Preoperative embolization of giant sacrococcygeal teratoma in a premature newborn. J Pediatr Surg 46(1):e5-e8. https://doi.org/10.1016/j.jpedsurg.2010. 09.038

Le N, Rivard DC, Rentea RM, Manalang M, Andrews W, Kane B, Hendrickson RJ (2018) Right trisegmentectomy after portal vein embolization in a high-risk toddler with hepatoblastoma. Pediatr Surg Int 34(5):573-578. https://doi.org/ 10.1007/s00383-018-4250-4

Leahey A (2012) A cautionary tale: dosing chemotherapy in infants with retinoblastoma. J Clin Oncol 30(10):1023-1024. https://doi.org/10.1200/JCO. 2011.39.4254

Li JP, Chu JP, Yang JY, Chen W, Wang Y, Huang YH (2008) Preoperative transcatheter selective arterial chemoembolization in treatment of unresectable hepatoblastoma in infants and children. Cardiovasc Intervent Radiol 31(6):1117-1123. https://doi.org/10.1007/s00270-008-9373-X

Li MJ, Tang DX, Xu S, Huang Y, Wu DH, Wang JH, Lai C, Tang HF, Shu Q (2016) Neoadjuvant Transcatheter arterial chemoembolization and systemic chemotherapy for the treatment of Wilms Tumor. In: van den Heuvel-Eibrink MM (ed) Wilms Tumor, Brisbane. https://doi.org/10.15586/codon.wt.2016.ch7

Li MJ, Zhou YB, Huang Y, Tang DX, Xu S, Wu DH, Zhang YY, Tang HF (2011) A retrospective study of the preoperative treatment of advanced Wilms tumor in children with chemotherapy versus transcatheter arterial chemoembolization alone or combined with short-term systemic 
chemotherapy. J Vasc Interv Radiol 22(3):279-286. https://doi.org/10.1016/j. jvir.2010.11.025

Liapi E, Geschwind JF (2007) Transcatheter and ablative therapeutic approaches for solid malignancies. J Clin Oncol 25(8):978-986. https://doi.org/10.1200/ JCO.2006.09.8657

Litten JB, Tomlinson GE (2008) Liver tumors in children. Oncologist 13(7):812-820. https://doi.org/10.1634/theoncologist.2008-0011

Lungren MP, Towbin AJ, Roebuck DJ, Monroe EJ, Gill AE, Thakor A, Towbin RB, Cahill AM, Matthew Hawkins C (2018) Role of interventional radiology in managing pediatric liver tumors : part 1: endovascular interventions. Pediatr Radiol 48(4):555-564. https://doi.org/10.1007/s00247-018-4068-1

Malogolowkin MH, Stanley P, Steele DA, Ortega JA (2000) Feasibility and toxicity of chemoembolization for children with liver tumors. J Clin Oncol 18(6): 1279-1284. https://doi.org/10.1200/JCO.2000.18.6.1279

Manjandavida FP, Stathopoulos C, Zhang J, Honavar SG, Shields CL (2019) Intraarterial chemotherapy in retinoblastoma - a paradigm change. Indian J Ophthalmol 67(6):740-754. https://doi.org/10.4103/ijo.IJO_866_19

Mavrogenis AF, Rossi G, Rimondi E, Calabro T, Papagelopoulos PJ, Ruggieri P (2014) Palliative embolization for osteosarcoma. Eur J Orthop Surg Traumatol 24(8):1351-1356. https://doi.org/10.1007/s00590-013-1312-0

Mutabagani KH, Klopfenstein KJ, Hogan MJ, Caniano DA (1999) Metastatic paraganglioma and paraneoplastic-induced anemia in an adolescent: treatment with hepatic arterial chemoembolization. J Pediatr Hematol Oncol 21(6):544-547

Oliveira C, Gil-Agostinho A, Goncalves I, Noruegas MJ $(2015,2015)$ Transarterial embolisation of a large focal nodular hyperplasia, using microspheres, in a paediatric patient. BMJ Case Rep. https://doi.org/10.1136/bcr-2014-208879

Owen RJ (2010) Embolization of musculoskeletal bone tumors. Semin Interv Radiol 27(2):111-123. https://doi.org/10.1055/s-0030-1253510

Pazionis TJ, Papanastassiou ID, Maybody M, Healey JH (2014) Embolization of hypervascular bone metastases reduces intraoperative blood loss: a casecontrol study. Clin Orthop Relat Res 472(10):3179-3187. https://doi.org/10 1007/s11999-014-3734-3

Pearl MS, Wolinsky JP, Gailloud P (2012) Preoperative embolization of primary spinal aneurysmal bone cysts by direct percutaneous intralesional injection of n-butyl-2-cyanoacrylate. J Vasc Interv Radiol 23(6):841-845. https://doi.org/ 10.1016/j.jvir.2012.02.005

Pio L, Avanzini S, Gandolfo C, Martucciello G, Granata C, Boscarelli A, Garaventa A, Mattioli G (2017) Successful treatment of neuroblastoma in an adolescent with intra-arterial embolization before surgery. J Pediatr Surg Case Rep 20:46. https://doi.org/10.1016/j.epsc.2017.02.015

Qin H, Yang S, Cai S, Ren Q, Han W, Yang W, Cheng H, Ma X, Wang H (2020) Clinical characteristics and risk factors of 47 cases with ruptured neuroblastoma in children. BMC Cancer 20(1):243. https://doi.org/10.1186/ s12885-020-06720-9

Rimon U, Duvdevani M, Garniek A, Golan G, Bensaid P, Ramon J, Morag B (2006) Ethanol and polyvinyl alcohol mixture for transcatheter embolization of renal angiomyolipoma. AJR Am J Roentgenol 187(3):762-768. https://doi.org/10. 2214/AJR.05.0629

Rossi G, Rimondi E, Bartalena T, Gerardi A, Alberghini M, Staals EL, Errani C, Bianchi G, Toscano A, Mercuri M, Vanel D (2010) Selective arterial embolization of 36 aneurysmal bone cysts of the skeleton with N-2-butyl cyanoacrylate. Skelet Radiol 39(2):161-167. https://doi.org/10.1007/s00256009-0757-z

Sharma R, Kitchen BJ, Mody R, Chamdin A, Bruch S, Jasty R (2013) A report of renal artery embolization for hematuria facilitating neoadjuvant chemotherapy in an unresectable malignant renal rhabdoid tumor. Pediatr Surg Int 29(5):533-535. https://doi.org/10.1007/s00383-013-3260-5

Shields CL, Shields JA (2010) Intra-arterial chemotherapy for retinoblastoma: the beginning of a long journey. Clin Exp Ophthalmol 38(6):638-643. https://doi. org/10.1111/j.1442-9071.2010.02297.x

Smith NP, Jesudason EC, McDowell HP, Rowlands P, Ashworth M, Losty PD (2005) Emergent embolisation to control severe haematuria in Wilms' tumour. Pediatr Surg Int 21(4):313-315. https://doi.org/10.1007/s00383-005-1402-0

Stavropoulou D, Hentschel R, Radecke J, Kunze M, Niemeyer C, Uhl M, Grohmann J (2019) Preoperative selective embolization with vascular coiling of giant sacrococcygeal teratoma. J Neonatal Perinatal Med 12(3):345-349. https://doi. org/10.3233/NPM-180066

Sun JH, Nie CH, Zhang YL, Zhou GH, Ai J, Zhou TY, Zhu TY, Zhang AB, Wang WL, Zheng SS (2015) Transcatheter arterial embolization alone for Giant hepatic Hemangioma. PLoS One 10(8):e0135158. https://doi.org/10.1371/journal.pone. 0135158
Tan X, Zhang J, Wen Z, Zou Y, Shen G, Zhou S, Li H, Jiang H (2014) Preoperative transcatheter arterial chemoembolization of hepatoblastoma in infants. J Vasc Interv Radiol 25(7):1029-1035. https://doi.org/10.1016/j.jvir.2014.03.032

Temple M, Marshalleck F (2014) Pediatric interventional radiologyhandbookofvascularandnon-vascularinterventions. Springer Science + Business Media, New York

Terraz S, Ronot M, Breguet R, Anooshiravani M, Rubbia-Brandt L, Becker CD, Wildhaber BE (2015) Portal vein embolization before extended hepatectomy in a toddler with Mesenchymal Hamartoma. Pediatrics 136(4):e1055-e1059. https://doi.org/10.1542/peds.2015-0179

Tsochatzis EA, Fatourou E, O'Beirne J, Meyer T, Burroughs AK (2014) Transarterial chemoembolization and bland embolization for hepatocellularcarcinoma. World J Gastroenterol 20(12):3069-3077. https://doi.org/10.3748/wjg.v20.i12. 3069

Veal GJ, Boddy AV (2012) Chemotherapy in newborns and preterm babies. Semin Fetal Neonatal Med 17(4):243-248. https://doi.org/10.1016/j.siny.2012.03.002

Venkatramani R, Wang L, Malvar J, Dias D, Sposto R, Malogolowkin MH, Mascarenhas $L$ (2012) Tumor necrosis predicts survival following neoadjuvant chemotherapy for hepatoblastoma. Pediatr Blood Cancer 59(3):493498. https://doi.org/10.1002/pbc.24038

Vogl TJ, Scheller A, Jakob U, Zangos S, Ahmed M, Nabil M (2006) Transarterial chemoembolization in the treatment of hepatoblastoma in children. Eur Radiol 16(6):1393-1396. https://doi.org/10.1007/s00330-005-2827-5

Wang HH, Luo CB, Guo WY, Wu HM, Lirng JF, Wong TT, Lu YH, Chang FC (2013) Preoperative embolization of hypervascular pediatric brain tumors: evaluation of technical safety and outcome. Childs Nerv Syst 29(11):2043-2049. https:// doi.org/10.1007/s00381-013-2128-2

Weiss KE, Sze DY, Rangaswami AA, Esquivel CO, Concepcion W, Lebowitz EA, Kothary N, Lungren MP (2018) Transarterial chemoembolization in children to treat unresectable hepatocellular carcinoma. Pediatr Transplant 22(4):e13187. https://doi.org/10.1111/petr.13187

Wu DH, Li MJ, Tang DX, Xu S, Huang Y, Wang JH, Shu Q (2016) Neoadjuvant Intraarterial chemotherapy for treatment of malignant vaginal tumors in children: a single-center experience. J Vasc Interv Radiol 27(7):996-1000. https://doi.org/10.1016/j.jvir.2016.03.025

Wyse E, Handa JT, Friedman AD, Pearl MS (2016) A review of the literature for intra-arterial chemotherapy used to treat retinoblastoma. Pediatr Radiol 46(9): 1223-1233. https://doi.org/10.1007/s00247-016-3554-6

Yamada K, Shinmoto H, Kawamura Y, Wakamatsu H, Kawauchi T, Soga S, Ogata S, Kaji T (2015) Transarterial embolization for pediatric hepatocellular carcinoma with cardiac cirrhosis. Pediatr Int 57(4):766-770. https://doi.org/10.1111/ped. 12619

\section{Publisher's Note}

Springer Nature remains neutral with regard to jurisdictional claims in published maps and institutional affiliations.

\section{Submit your manuscript to a SpringerOpen ${ }^{\circ}$ journal and benefit from:}

- Convenient online submission

- Rigorous peer review

- Open access: articles freely available online

High visibility within the field

- Retaining the copyright to your article

Submit your next manuscript at $>$ springeropen.com 